\title{
Acceleration of HIV dementia with methamphetamine and cocaine
}

\author{
Avindra Nath*,1,2, William F Maragos ${ }^{1,3}$, Malcolm J Avison ${ }^{1}$, Frederick A Schmitt ${ }^{1}$ and Joseph R Berger ${ }^{1}$ \\ ${ }^{1}$ Department of Ne urology, University of Kentucky, Lexington, KY 40526-0284, USA; ${ }^{2}$ Department of Microbiology and \\ Immunology, University of Kentucky, Lexington, KY 40526-0284, USA and ${ }^{3}$ Ana tomy and Neurobiology, University of \\ Kentucky, Lexington, KY 40526-0284, USA
}

\begin{abstract}
We report a patient with rapidly accelerating HIV dementia accompanied by seizures and an unusual movement disorder despite highly potent antiretroviral therapy. This clinical constellation was associated with the non-parenteral use of methamphetamine and cocaine. Fractional enhancement time on post contrast magnetic resonance imaging studies revealed a progressive breakdown of the blood brain barrier particularly in the basal ganglia. The movement disorder but not the dementia responded to a combination of dopamine replacement and anticholinergic therapy. While the movement disorder may have been unmasked by concomitant anticonvulsant therapy, we suggest in this instance, that prior drug abuse synergized with HIV to cause a domino effect on cerebral function. Careful attention and analysis to histories of remote noninjecting drug abuse may help substantiate our hypothesis. Journal of Neuro Virology (2001) 7, 66-71.
\end{abstract}

Keywords: HIV; brain; AIDS; cocaine; methamphetamine

\section{Introduction}

Recent evidence suggests that the HIV epidemic is in part being driven by drug abuse. This group of individuals is the fastest growing population with HIV infection in the United States and Western European countries, yet, very little is known about the potential interaction of these drugs with HIV infection in the genesis of cerebral dysfunction. The observation of an increased frequency of HIV encephalitis at autopsy among drug abusers (Bell et al, 1998) suggests that a relationship between these drugs of abuse and HIV infection exists. We report the constellation of HIV dementia, seizures and an unusual movement disorder that developed in association with the non-parenteral use of methamphetamine and cocaine. The movement disorder but not the dementia responded to treatment with L-DOPA and anticholinergic therapy. We discuss possible pathophysiological mechanisms that might contribute to the interactions of drugs of abuse and HIV infection on cerebral function.

* Correspondence: A Nath

Received 24 March 2000; revised 15 July 2000; accepted 23 August 2000

\section{Results}

Case report

We report ED, a 44 year old HIV seropositive man with a 10 year history of recreational use (every weekend) of methamphetamine (oral) and cocaine (intra-nasal). HIV seropositivity was initially demonstrated in March 1995, when he developed pneumocystis pneumonia. CD4 cell count at that time was 0 cells $/ \mu$ l of blood. In August 1998, after 3 years of highly active antiretroviral therapy he developed generalized seizures. MRI scan revealed cerebral and basal ganglia atrophy with diffuse white matter high signal intensity lesions on T2 weighted images (Figure 1). EEG showed left temporal spikes and rhythmic delta waves. CSF showed 20 white blood cells $/ \mu 1$, (all mononuclear), 2 red blood cells $/ \mu 1$, protein of $55 \mathrm{mg} / \mathrm{dl}$, glucose of $50 \mathrm{mg} / \mathrm{dl}$. The CSF IgG index was elevated at 2.56 (normal $0.28-0.66$ ) and oligoclonal bands were present but myelin basic protein was normal at 0.2 (range 0-2.3 ng/ml). After August 1998, his CD4 cell count ranged from $50-200$ cells $/ \mathrm{mm}^{3}$ of blood and HIV load ranged from 300-1000 RNA copies / $\mathrm{ml}$ of plasma. He scored 10/16 on the HIV Dementia Scale (Power et al, 1995) and 2 on the Memorial Sloan Kettering Scale (Price and Brew, 1988) 

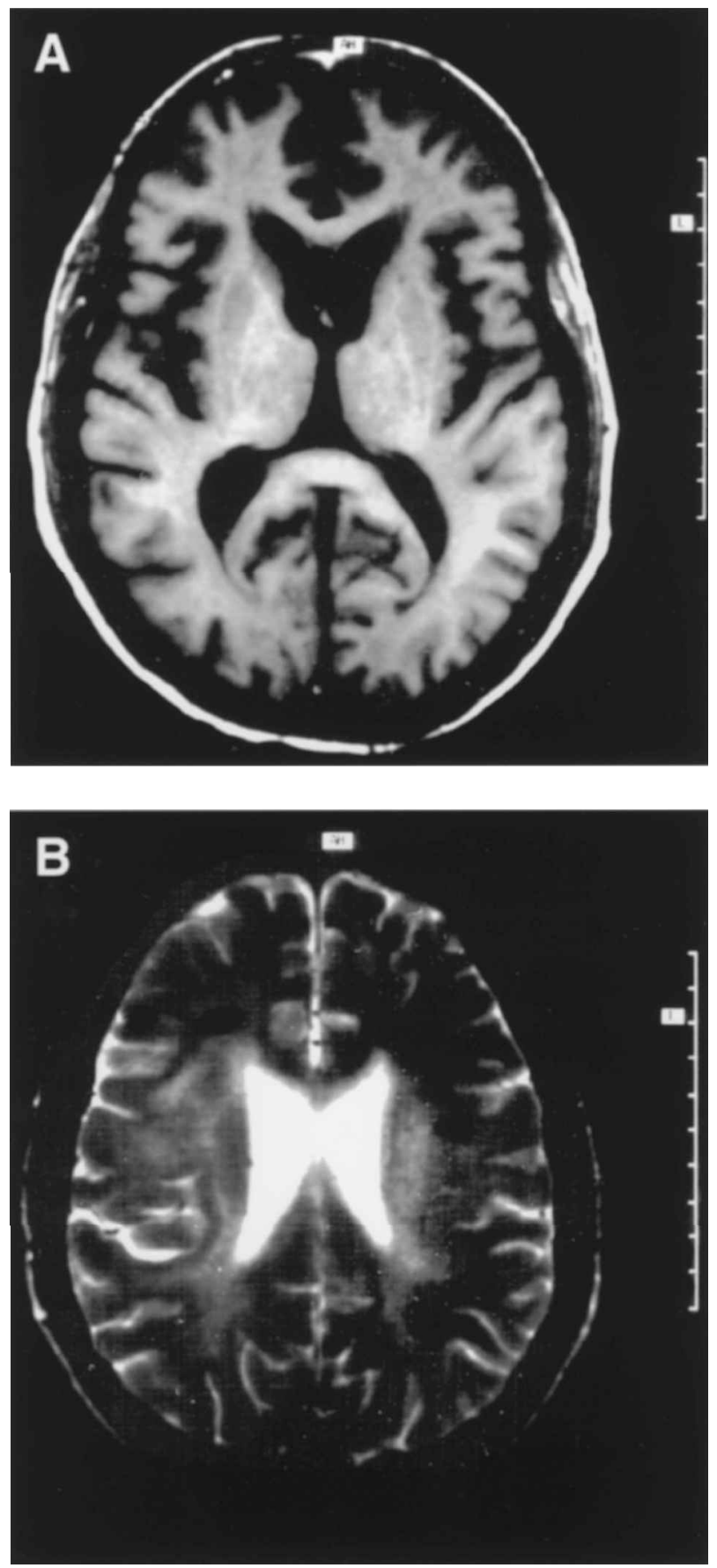

Figure 1 MRI scan. (A) Generalized cerebral atrophy most prominent in the frontal and temporal regions as well as basal ganglia atrophy with shrinkage of the head of the caudate is noted. (B) Diffuse periventricular white matter high signal intensity lesions are seen on a T2 weighted image.

suggestive of a moderate HIV dementia. Repeat neurophyschological evaluations showed progressive impairment with severely delayed recall and moderate abnormalities in learning, attention and concentration. His seizures were controlled on phenytoin and gabapentin. Drug levels for pheny- toin remained in the therapeutic range $(10-20 \mathrm{mg} /$ L) for the duration of follow-up, although free levels were not measured.

The patient stopped cocaine use after the onset of the first seizure and methamphetamine use 3 months later. In April 1999, he developed a painful focal dystonia with flexion at the right wrist, spooning of the fingers most prominent on extension of the hands, choreoathetosis of the fingers, coarse resting tremor of the hands (greater on the left) with cogwheel rigidity and postural instability. There was no history of exposure to neuroleptics. This patient was extensively investigated for all other causes of dementia and movement disorders including thyroid function tests, vitamin B12, folate levels, serum copper and ceruloplasmin levels, RPR, a complete vasculitis work up, blood smear for acanthosis, and complete blood chemistry with liver function tests. All were negative or normal.

Analysis of the time course of post-contrast enhancement in the striatum 3 months prior to and 3 weeks following the onset of motor symptoms (Figure 2) revealed that FE30 which was elevated (0.018) relative to non-demented HIV infected volunteers $(\mathrm{FE} 30=0.002 \pm 0.001)$ when the patient was first studied, had become markedly elevated $($ FE30 $=0.033)$ when the patient was restudied $\sim 4$ months later following the onset of motor symptoms. FEmax data were not available when the patient was first studied, due to motion artifacts in the early part of the study. However, when the patient was restudied following the onset of motor symptoms, FEmax was not significantly different from that found in non-demented HIV infected

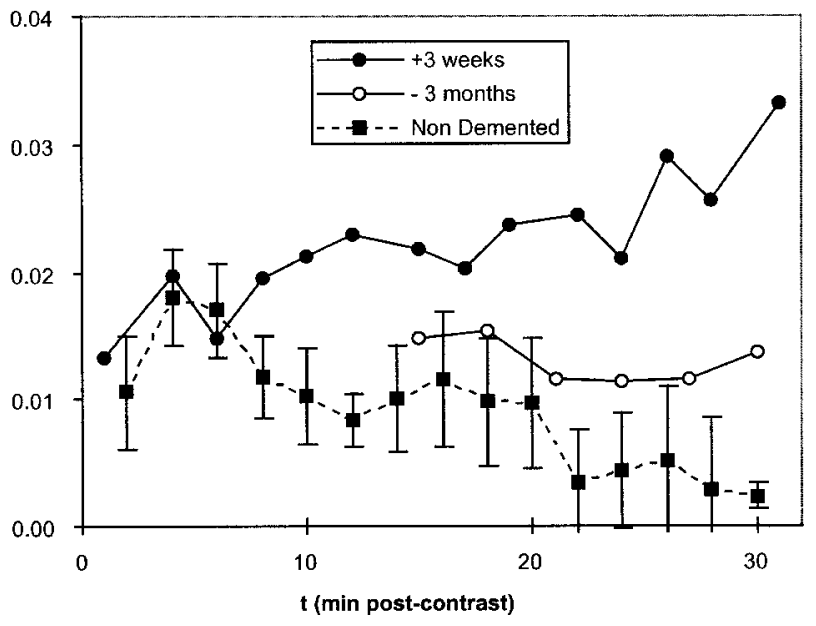

Figure 2 Time course of post-contrast fractional enhancement in basal ganglia of Patient ED studied 3 months prior to, and 3 weeks following development of motor symptoms. Basal ganglia fractional enhancement (FEbg) is normalized to fractional enhancement in sagittal sinus (FEss). Data from a group of non-demented HIV positive patients $(n=4)$ are also shown for comparison (see Berger et al., 2000). 
volunteers. These results suggest progressive decline in BBB integrity in the basal ganglia accompanied the onset of motor symptoms, but minimal alteration in basal ganglia vascularity. Treatment of the dystonia associated pain with a variety of nonnarcotic and narcotic analgesics was ineffective. However, the movement disorder and the pain responded dramatically to treatment with Sinemet (carbidopa/L-dopa) 10/100, three times daily and artane (6 mg/day). The pain resolved within 1 week of treatment and the involuntary movements improved within 2-3 weeks. There was a partial resolution of the postural instability but no effect on his cognitive impairment.

\section{Discussion}

This case report illustrates several important features. There was a progressive decline of neuropsychological functioning despite aggressive antiretroviral therapy and control of viral load. This was associated with cerebral and basal ganglia atrophy, diffuse white matter changes, a left temporal seizure focus and mild CSF pleocytosis with intrathecal synthesis of immunoglobulins. These observations are consistent with a rapidly progressive HIV dementia that is usually associated with poor prognosis (Bouwman et al, 1998). Antiretroviral therapy has been shown to reverse the neropsychological manifestations of HIV dementia in some patients (Gendelman et al, 1998) and has had a positive impact on the natural history of HIV dementia (Price et al, 1999; Sacktor et al, 1999). However, as illustrated by this case report, severe and progressive HIV dementia may occur despite the use of highly potent antiretroviral therapy. Antiretroviral drugs, in general, poorly penetrate the blood brain barrier (Aweeka et al, 1999), hence, it is possible that once HIV-infected or activated macrophages enter the brain, antiretroviral therapy may not have a major impact on the neuropathogenesis of HIV infection. The role of drug abuse in this apparent failure of antiretroviral therapy needs further study.

Studies addressing the frequency of HIV dementia in drug abusers have produced variable results. While Italian investigators (Grassi et al, 1997) found a profound negative influence of drug abuse on cognitive function among HIV-infected persons, the Johns Hopkins group did not report a difference in the incidence of dementia in HIV-infected drug users (Concha et al, 1992, 1997; Selnes et al., 1997). A subsequent study showed that a history of injection drug use and presentation with prominent psychomotor slowing was associated with more rapid neurologic progression and that these patients had more abundant macrophage activation within the CNS (Bouwman et al, 1998). Pathological studies from a cohort in Scotland (Bell et al, 1998) revealed that $56 \%$ of the brains of HIV-infected drug users had features of HIV encephalitis evidenced by the presence of HIV p24 and multinucleated giant cells in comparison to only $17 \%$ of homosexual HIV-infected men coming to autopsy. These studies support the notion that, although drug abuse may not have a dramatic effect on the incidence of dementia, once HIV neurocognitive impairment does occur, drug abuse may cause or initiate a rapid and severe decline in cerebral function as seen in this case report.

The basal ganglia face the major brunt of HIV infection in the brain. Multinucleated giant cells, microglial nodules, and HIV-infected microglial cells and infiltrating macrophages are most prominent in the basal ganglia, compared to other regions within the brain (Navia et al, 1986). Viral load is also maximal in this region (Fujimura et al, 1997). Significant neuronal cell loss, is also noted in the pars compacta of the substantia nigra (Reyes et al, 1991). Low levels of dopamine are also present in the caudate nucleus of patients with AIDS (Sardar et al, 1996). CSF homovanillic acid levels are diminished in patients with AIDS and more severely so in patients with AIDS dementia (Berger et al, 1994; Larsson et al, 1991). HIV neurotoxic proteins Tat and gp120 can both be detected in the basal ganglia of patients with HIV encephalitis (Hofman et al, 1994; Kruman et al, 1999; Nath et al, 2000). Injection of Tat into the lateral ventricle in rats causes apoptosis of stiatal neurons (Jones et al, 1998). Injection of Tat into the striatum, leads to loss of striatal $\mathrm{N}$-acetyl aspartate peak by nuclear magnetic resonance spectroscopy (Berger and Nath, 1997) and loss of niagrostiatal fibers (Hayman et al, 1993). Consistent with these pathological observations, patients with HIV infection may develop a variety of movement disorders (reviewed in Berger and Nath, 1997). To date, however, the combination of motor abnormalities manifesting as focal dystonia, choreoathetosis and resting tremor abnormalities in a single patient have not been reported to the best of our knowledge. This constellation of signs suggests the possibility that the combination of drug abuse and HIV infection may have contributed to the aggressive and unusual course of HIV dementia with prominent effects on the basal ganglia.

Drugs of abuse such as cocaine and methamphetamine may interact with HIV in several different ways to accelerate the neurological complications of HIV infection. Cocaine has been shown to cause a breakdown of the blood brain barrier resulting in increased trafficking of monocytes and virus into the brain (Fiala et al, 1998). MRI studies in the present case report also showed a significant break down of the blood brain barrier in the striatum. These drugs may also have direct effects on neurons. Amphetamines potentiate the release of dopamine into the synaptic cleft. Cocaine is a nonselective inhibitor of dopamine uptake, acting 
through inhibition of the dopamine transporter. Inhibition of the transporter results in a rapid increase of dopamine in the synaptic cleft, which has been hypothesized to underlie the euphoric 'rush' that accompanies cocaine abuse. Chronic amphetamine and cocaine use, thus, deplete the dopamine pools and are associated with reduced levels of striatal dopamine and the dopaminergic transporter in humans (Wilson et al, 1996a, b). A single dosing of methamphetamine may be sufficient to cause dopamine neurotoxicity as evidenced by the loss of dopamine transporter detection by positron emission tomography (Villemagne et al, 1998). Recent studies show that chronic methamphamine use is associated with neurodegeneration as determined by MRS studies. (Ernst et al, 2000). We have also shown that methamphetamine and cocaine may synergize to cause neurotoxicity (Nath et al, in press).

Importantly, this patient showed rapid progression of HIV dementia even after he abstained from drugs of abuse. It has been shown that remote exposure to neurotoxins may be sufficient to cause progressive neurodegeneration in humans (Langston et al, 1999). Although it is possible that the progression may have been impacted by factors other than drug abuse, for example, viral strains have been associated with neurovirulence (Power $e t$ al, 1994), other possibilities need to be also considered. While anticonvulsants have also been associated with movement disorders it is a rare idiosyncratic phenomenon, particularly in patients with therapeutic anticonvulsants levels (Harrison $e t$ $a l, 1993$. However, it is possible that the use of phenytoin and gabapentin in this patient may have unmasked the underlying basal ganglia pathology.

Once the blood brain barrier has been broken down as may occur with cocaine use (Fiala et al, 1998), and HIV infected or activated macrophages enter the brain (Bouwman et al, 1998) they may set up positive feed back loops (Nath and Geiger, 1998) that would not require continuous exposure to drugs of abuse. Clinical and experimental studies show that progressive neurological deterioration may continue for days to years even when exposure to neurotoxic substances have been removed (Jones et al, 1998; Langston et al, 1999; Nath et al, 1999). Hence it is easy to postulate that viral and cellular products released from HIV infected cells may synergize with drugs of abuse such as methamphetamine and cocaine to cause an initial insult to the brain and then cause a domino effect.

\section{Conclusions}

We thus conclude that methamphetamine and cocaine may contribute to the acceleration of HIV dementia and the use of anticonvulsants may unmask an underlying basal ganglia lesion. Careful screening of all patients with HIV infection for drugs of abuse may be necessary. Further studies are needed to determine the extent to which noninjection drug users and recreational drugs users may also be at significant risk of developing HIV dementia and to determine the mechanisms involved in these synergistic interactions.

\section{Materials and methods}

Blood brain barrier assessment

MRIs were performed on a 1.5 T Siemens Magnetom Vision MR system (Siemens Medical Systems, Iselin, NJ, USA) using a standard, circularly polarized head coil at 3 months prior to, and 3 weeks after the onset of motor symptoms in this patient. Following a standard series of T1 and T2 weighted scans to identify/rule out neurologically significant structural lesions, the time course of post-contrast enhancement was determined in the basal ganglia, to study blood brain barrier integrity.

MRI sequence parameters: The following sequences were used for the standard work up: THK $=5 \mathrm{~mm}, 3 \%$ interslice gap, $F O V=230 \mathrm{~mm}$, $\mathrm{MA}=192 \times 256$. PD/T2 weighted spin echo (axial): $\mathrm{TR} / \mathrm{TE} 1 / \mathrm{TE} 2=2000 / 20 / 80 \mathrm{~ms}, \mathrm{FA}=65^{\circ}, \mathrm{FOV}=256 \times$ $256 \times 180 \mathrm{~mm}, \mathrm{MA}=128 \times 128 \times 90$. T1 weighted 3D FLASH: TR $/ \mathrm{TE}=21 / 6 \mathrm{~ms}, \mathrm{FA}=30^{\circ}$, THK $=5 \mathrm{~mm}$, $30 \%$ interslice gap, $\mathrm{FOV}=230 \mathrm{~mm}, \mathrm{MA}=192 \times 256$. PD weighted spin echo (axial): TR/TE $=2000 / 14 \mathrm{ms,}$ $\mathrm{FA}=62^{\circ}$, $\mathrm{THK}=5 \mathrm{~mm}, 3 \%$ interslice gap, $\mathrm{FOV}=$ $230 \mathrm{~mm}, \mathrm{MA}=192 \times 256$. T1 weighted spin echo (axial, pre- and post-contrast): TR/TE $=610 / 14 \mathrm{ms,}$ $\mathrm{FA}=62^{\circ}, \mathrm{THK}=5 \mathrm{~mm}, 3 \%$ interslice gap, $\mathrm{FOV}=$ $230 \mathrm{~mm}, \mathrm{MA}=192 \times 256$. Fixed receiver and reconstruction gains.

MRI post-contrast protocol: Axial $\mathrm{T} 1$ weighted spin echo sequence was used to acquire three precontrast image sets, from which mean values were derived. Contrast agent (gadolinium-DTPA; Magnevist ${ }^{\otimes} 0.1 \mathrm{mmol} / \mathrm{kg}$ i.v.) was then administered, and post-contrast T1 weighted images using identical acquisition parameters were obtained. Images were collected without interruption (one set every $\sim 2 \mathrm{~min}$ ) for at least $30 \mathrm{~min}$ post contrast.

MRI data analysis: For a given region of interest (ROI), the fractional enhancement at time $t$ postcontrast was defined as $\mathrm{FE}(\mathrm{t})=(\mathrm{S}(\mathrm{t})-\mathrm{S}($ pre $)) / \mathrm{S}$ (pre), where $S(t)$ was the mean MRI signal in the ROI at time $t$ post-contrast, and $S$ (pre) was the mean MRI signal in the same ROI prior to contrast administration. Mean FE was determined for the basal ganglia and adjacent white matter as follows: Region-ofinterest (ROI) measurements for each time point 
pre- and post-contrast were collected using a mask traced to outline basal ganglia structures. These ROI measurements were combined to determine the mean FE in subcortical gray matter. To account for study to study variations in contrast dose, and to assess the contribution of differences in rCBV to the post contrast enhancement, these FEs were normalized to the FE in the sagittal sinus at the same time post-contrast. The maximal normalized FE (FEmax), occurring immediately following contrast administration, and the normalized FE 30 min post contrast (FE30), were used as surrogate indices of

\section{References}

Aweeka F, Jayewardene A, Staprans S, Bellibas SE, Kearney B, Lizak P, Novakovic-Agopian T, Price RW (1999). Failure to detect nelfinavir in the cerebrospinal fluid of HIV-1-infected patients with and without AIDS dementia complex. I Acquir Immune Defic Syndr Hum Retrovirol 20: 39-43.

Bell JE, Brettle RP, Chiswick A, Simmonds P (1998). HIV encephalitis, proviral load and dementia in drug users and homosexuals with AIDS. Effect of neocortical involvement. Brain 121: $2043-2052$.

Berger JR, Kumar M, Kumar A, Fernandez JB, Levin B (1994). Cerebrospinal fluid dopamine in HIV-1 infection. AIDS 8: $67-71$.

Berger JR, Nath A (1997). HIV dementia and the basal ganglia. Intervirology 40: $122-131$.

Berger JR, Nath A, Greenberg RN, Andersen AH, Greene RA, Bognar A, Avison MJ (2000). Cerebrovascular changes in the basal ganglia with HIV dementia. Neurology 54: $921-926$.

Bouwman FH, Skolasky RL, Hes D, Selnes OA, Glass JD, Nance-Sproson TE, Royal W, Dal Pan GJ, McArthur JC (1998). Variable progression of HIV-associated dementia. Neurology 50: $1814-1820$.

Concha M, Graham NM, Munoz A, Vlahov D, Royal WD, Updike M, Nance-Sproson T, Selnes OA, McArthur JC (1992). Effect of chronic substance abuse on the neuropyschological performance of intravenous drug users with a high prevalence of HIV-1 seropositivity. Am J Epidemiol 136: $1338-1348$.

Concha M, Selnes OA, Vlahov D, Nance-Sproson T, Updike M, Royal W, Palenicek J, McArthur JC (1997). Comparison of neuropsychological performance between AIDS-free injecting drug users and homosexual men. Neuroepidemiology 16: $78-85$.

Ernst T, Chang L, Leonido-Yee M, Speck O (2000). Evidence of long term neurotoxicity associated with methamphetamine abuse. A $1 \mathrm{H}$ MRS study. Neurology 54: $1344-1349$.

Fiala M, Gan XH, Zhang L, House SD, Newton T, Graves MC, Shapshak P, Stins M, Kim KS, Witte M, Chang SL (1998). Cocaine enhances monocyte migration across the blood-brain barrier. Cocaine's connection to AIDS dementia and vasculitis? Adv Exp Med Biol 437: $199-205$. basal ganglia CBV and blood brain barrier permeability respectively.

\section{Acknowledgements}

The authors thank Robin Avison for technical assistance with MRI studies, Alice Thornton and Gregory Pittman for referring the patient and Rosemarie Booze, Kurt Hauser and Charles Mactutus for helpful comments. This study was supported in part by NIH grants to A Nath, W Maragos, M Avison, F Schmitt.

Fujimura RK, Goodkin K, Petito CK, Douyon R, Feaster DJ, Concha M, Shapshak P (1997). HIV-1 proviral DNA load across neuroanatomic regions of individuals with evidence for HIV-1-associated dementia. $J$ Acquir Immune Defic Syndr Hum Retrovirol 16: $146-$ 152.

Gendelman H, Zheng J, Coulter C, Ghorpade A, Che M, Thylin M, Rubocki R, Persidsky Y, Hahn F, Reinhard J, Swindells S (1998). The HIV-associated dementia complex: a metabolic encephalopathy reversed by highly active antiretroviral therapy. J Infect Dis 178: $1000-1007$.

Grassi MP, Perin C, Clerici F, Zocchetti C, Borella M, Cargnel A, Mangoni A (1997). Effects of HIV seropositivity and drug abuse on cognitive function. Eur Neurol 37: 48-52.

Harrison MB, Lyons GR, Landow ER (1993). Phenytoin and dyskinesias: a report of two cases and review of the literature. Mov Disord 8: 19-27.

Hayman M, Arbuthnott G, Harkiss G, Brace H, Filippi P, Philippon V, Thomson D, Vigne R, Wright A (1993). Neurotoxicity of peptide analogues of the transactivating protein tat from Maedia-Visna virus and human immunodeficiency virus. Neuroscience 53: 1-6.

Hofman FM, Dohadwala MM, Wright AD, Hinton DR, Walker SM (1994). Exogenous tat protein activates central nervous system-derived endothelial cells. J Neuroimmunol 54: 19-28.

Jones M, Olafson K, Del Bigio MR, Peeling J, Nath A (1998). Intraventricular injection of human immunodeficiency virus type 1 (HIV-1) Tat protein causes inflammation, gliosis, apoptosis, and ventricular enlargement. J Neuropathol Exp Neurol 57: 563-570.

Kruman II, Nath A, Maragos WF, Chan SL, Jones M, Rangnekar VM, Jakel RJ, Mattson MP (1999). Evidence that Par-4 participates in the pathogenesis of AIDS dementia. Am J Pathol 155: 39-46.

Langston JW, Forno LS, Tetrud J, Reeves AG, Kaplan JA, Karluk D (1999). Evidence of active nerve cell degeneration in the substantia nigra of humans years after 1-methyl-4-phenyl-1,2,3,6-tetrahydropyridine exposure. Ann Neurol 46: 598-605. 
Larsson M, Hagberg L, Forsman A, Norkrans G (1991). Cerebrospinal fluid catecholamine metabolites in hIVinfected patients. J Neurosci Res 28: 406-409.

Nath A, Conant K, Chen P, Scott C, Major EO (1999). Transient exposure to HIV-1 Tat protein results in cytokine production in macrophages and astrocytes: A hit and run phenomenon. J Biol Chem 274: 1709817102.

Nath A, Geiger JD (1998). Neurobiological aspects of HIV infections: neurotoxic mechanisms. Prog Neurobiol 54: $19-33$.

Nath A, Haughey NJ, Jones M, Anderson C, Bell JE, Geiger JD (2000). Synergistic neurotoxicity by human immunodeficiency virus proteins Tat and gp120: protection by memantine. Ann Neurol 47: 186-194.

Nath A, Jones M, W, M, Booze RM, Mactutus C, Bell J, Mattson M (2000). Neurotoxicity and Dysfunction of Dopaminergic Systems Associated with AIDS Dementia. J Psychopharmacology (in press).

Navia BA, Cho ES, Petiio CK, Price RW (1986). The AIDS dementia complex: II Neuropathology. Ann Neurol 19, 525-535.

Power C, McArthur JC, Johnson RT, Griffin DE, Glass JD, Perryman S, Chesebro B (1994). Demented and nondemented patients with AIDS differ in brainderived human immunodeficiency virus type 1 envelope sequences. J Virol 68: $4643-4649$.

Power C, Selnes OA, Grim JA, McArthur JC (1995). HIV Dementia Scale: a rapid screening test. J Acquir Immune Defic Syndr Hum Retrovirol 8: 273-278.

Price RW, Brew BJ (1988). The AIDS dementia complex. J Infect Dis 158: $1079-1083$.

Price RW, Yiannoutsos CT, Clifford DB, Zaborski L, Tselis A, Sidtis JJ, Cohen B, Hall CD, Erice A, Henry K (1999). Neurological outcomes in late HIV infection: adverse impact of neurological impairment on survival and protective effect of antiviral therapy. AIDS Clinical Trial Group and Neurological AIDS Research Consortium study team. AIDS 13: $1677-1685$.
Reyes MG, Faraldi F, Senseng CS, Flowers C, Fariello R (1991). Nigral degeneration in acquired immune deficiency syndrome (AIDS). Acta Neuropathol 82: $39-44$.

Sacktor NC, Lyles RH, Skolasky RL, Anderson DE, McArthur JC, McFarlane G, Selnes OA, Becker JT, Cohen B, Wesch J, Miller EN (1999). Combination antiretroviral therapy improves psychomotor speed performance in HIV-seropositive homosexual men. Multicenter AIDS Cohort Study (MACS). Neurology 52: $1640-1647$.

Sardar AM, Czudek C, Reynolds GP (1996). Dopamine deficits in the brain: the neurochemical basis of parkinsonian symptoms in AIDS. Neuroreport 7: $910-912$.

Selnes OA, Galai N, McArthur JC, Cohn S, Royal W, 3rd, Esposito D, Vlahov D (1997). HIV infection and cognition in intravenous drug users: long-term follow-up. Neurology 48: 223-230.

Villemagne V, Yuan J, Wong DF, Dannals RF, Hatzidimitriou G, Mathews WB, Ravert HT, Musachio J, McCann UD, Ricaurte GA (1998). Brain dopamine neurotoxicity in baboons treated with doses of methamphetamine comparable to those recreationally abused by humans: evidence from [11C]WIN-35,428 positron emission tomography studies and direct in vitro determinations. J Neurosci 18: 419-427.

Wilson JM, Kalasinsky KS, Levey AI, Bergeron C, Reiber G, Anthony RM, Schmunk GA, Shannak K, Haycock JW, Kish SJ (1996a). Striatal dopamine nerve terminal markers in human, chronic methamphetamine users. Nat Med 2: 699-703.

Wilson JM, Levey AI, Bergeron C, Kalasinsky K, Ang L, Peretti F, Adams VI, Smialek J, Anderson WR, Shannak K, Deck J, Niznik HB, Kish SJ (1996b). Striatal dopamine, dopamine transporter, and vesicular monoamine transporter in chronic cocaine users. Ann Neurol 40: 428-439. 